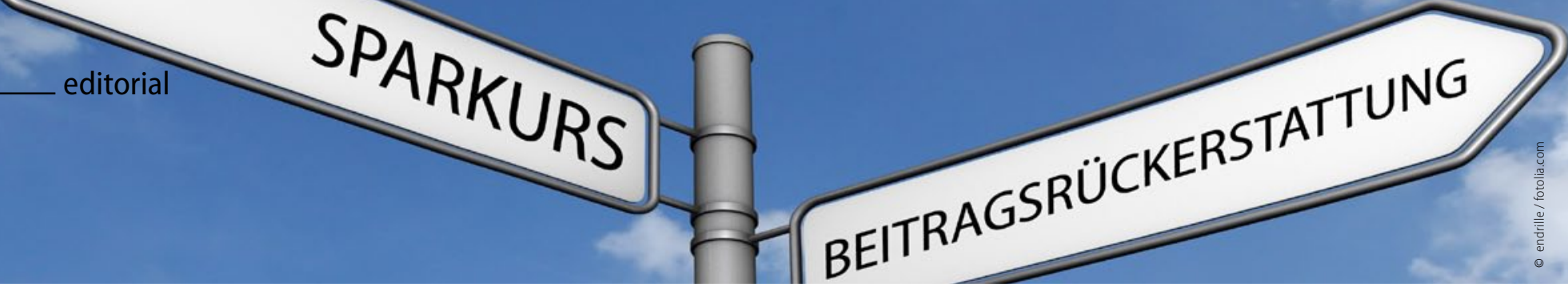

\title{
Viele Wege führen nach Rom - die Sklaverei für Ärzte geht weiter!
}

\author{
Die TK bietet Ihren Mitgliedern einen Bonus \\ von 80 Euro pro anno. Nicht für Leistung, \\ sondern für Mitgliedschaft. Eine Beitragsrück- \\ erstattung soll das sein.
}

Wir bieten den Versicherten dieser Kasse wie anderen GKV-Versicherten auch qualitativ hochwertige Medizin, ohne dafür eine adäquate Honorierung aus dem angesprochenen gut gefüllten Topf zu erhalten. 30 Milliarden sind im GKV-Sack nach neuesten Meldungen enthalten, gut (?) konserviert bei einer Teuerung von 2,5\% und einem Zinssatz nahe Null. Uns lässt man im GKVTopf schmoren, ja allergologisch verdorren, anstatt unser Honorar zumindest minimal der Teuerung anzupassen. Für die PKV gilt das Gleiche.

Gut sind die Kassen beim Kesseltreiben in der nachrichtenarmen Zeit: Flugs geht es gegen Igel-Leistungen; das Ansehen der Ärzte wird Schritt für Schritt untergraben, wir als Abzocker hingestellt. Dabei versuchen wir uns GKV- und PKV-konform zu verhalten: Medizinisch nicht notwendige Leistungen haben weder GKV- noch PKV-Versicherte zu beanspruchen. Diese Leistungen unterliegen einem gewissen Prozentsatz der Umsatzsteuer, wie die Medikamente in der GKV und PKV übrigens auch. Die GOÄ gilt laut unseren Experten auch für die medizinisch nicht notwendigen Leistungen, auch wenn in der Präambel der GOÄ diese ausdrücklich ausgeschlossen sind. Die GOÄ ist hilflos veraltet, plädiert man für ein Update, hört man stets „Bloß nicht rütteln“. Wie so oft bahnt sich bereits eine Lösung über die EU an.

Die Politiker tauchen vor der Wahl mit Ihren Aussagen unter: Nur niemandem weh tun! Wir erinnern uns an die Zeit vor und nach der vorletzten Bundestagswahl: Am Ende stieg die Mehrwertsteuer um 3\%. Egal wie hoch, zum Ausgleich der Schulden in der EU wird es nicht langen. Man wird uns erzählen, dass die Schuldenbremse im GG einen drastischen Sparkurs gebiete. Die Banken und Co. haben das Ihre längst in Sicherheit gebracht. Schade, dass unter diesen Zwängen die Freiheit des Einzelnen wie auch die FDP verloren gehen: Die große Koalition wird in Berlin längst vorbereitet. Zünglein an der Waage spielen eventuell auch die Freien Wähler. Wie es auch kommt, es kommt eher mit Bundeskanzlerin Angela Merkel als ohne. Ideal wäre es gewesen, wenn unsere Mannen in Berlin die GOÄ unter Dach und Fach in dieser Legislaturperiode gebracht hätten. Gleich am Beginn. Aber da werden wieder Spielchen gespielt, es geht um Einfluss und und und ... Die KBV verhandelt in einem Anflug scheinbarer Allmacht einen Basistarif der PKV unterhalb des 1,0-fachen der GÖ̈. Dafür gebührt ihr zeitlebens die rote Karte. Die Zahnärzte immerhin haben eine GOZ erreicht. Ob gut oder schlecht, wird sich zeigen. Ein Plus von 6\% ist ja nicht nichts. Hätten wir die GOÄ line-

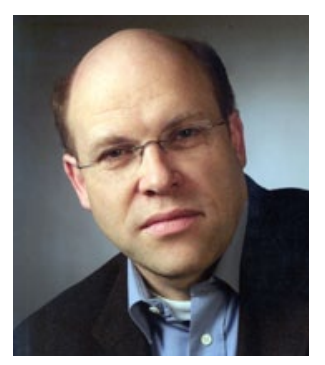

Dr. Matthias Herbst

ar mit einem Kaufkraftausgleich versehen, hätte es ebenfalls nichts geschadet und wäre schnell gegangen. So trödeln wir dahin, bis es zu spät ist und jeder „Gebührenexperte“ von fast $60 \mathrm{Be}$ rufsverbänden inkognito seine Duftnote gesetzt hat. Vereinfachung wäre angesagt: Keine berufspolitischen Tricks, sondern klare Fakten. Die einfache Wahrheit: Ein Tag hat 24 Stunden. Jede Arbeit beansprucht einen Teil davon. Daraus bildet man y Gruppen à $\mathrm{x}$ Minuten und schon hat man einen einheitlichen Bewertungsmaßstab. Für die KV-Bürokratie und die EDV-Industrie und ihre Geschäfte anscheinend zu einfach.

Für den Arzt kann es jedenfalls nicht einfach genug sein, weil er ja bekanntermaßen für den Patienten da sein will und hier schadet alles Komplizierte. So erwartet er von seinen Vertretern zu recht vollen Einsatz für die Interessen des Arztes vor Ort in der Praxis und keine Götterdämmerung in lichten KV-Höhen mit Komplettabsturz wie jüngst in Hessen.

Preisfrage: Was ändert sich nach der nächsten Wahl? Es kommt wie immer - alles wird teurer!

Bis zum nächsten Mal!

Herzlich

Ihr

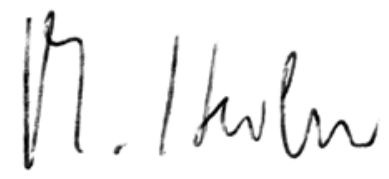

Dr. Matthias Herbst

Vorstand QSD e.V. 